
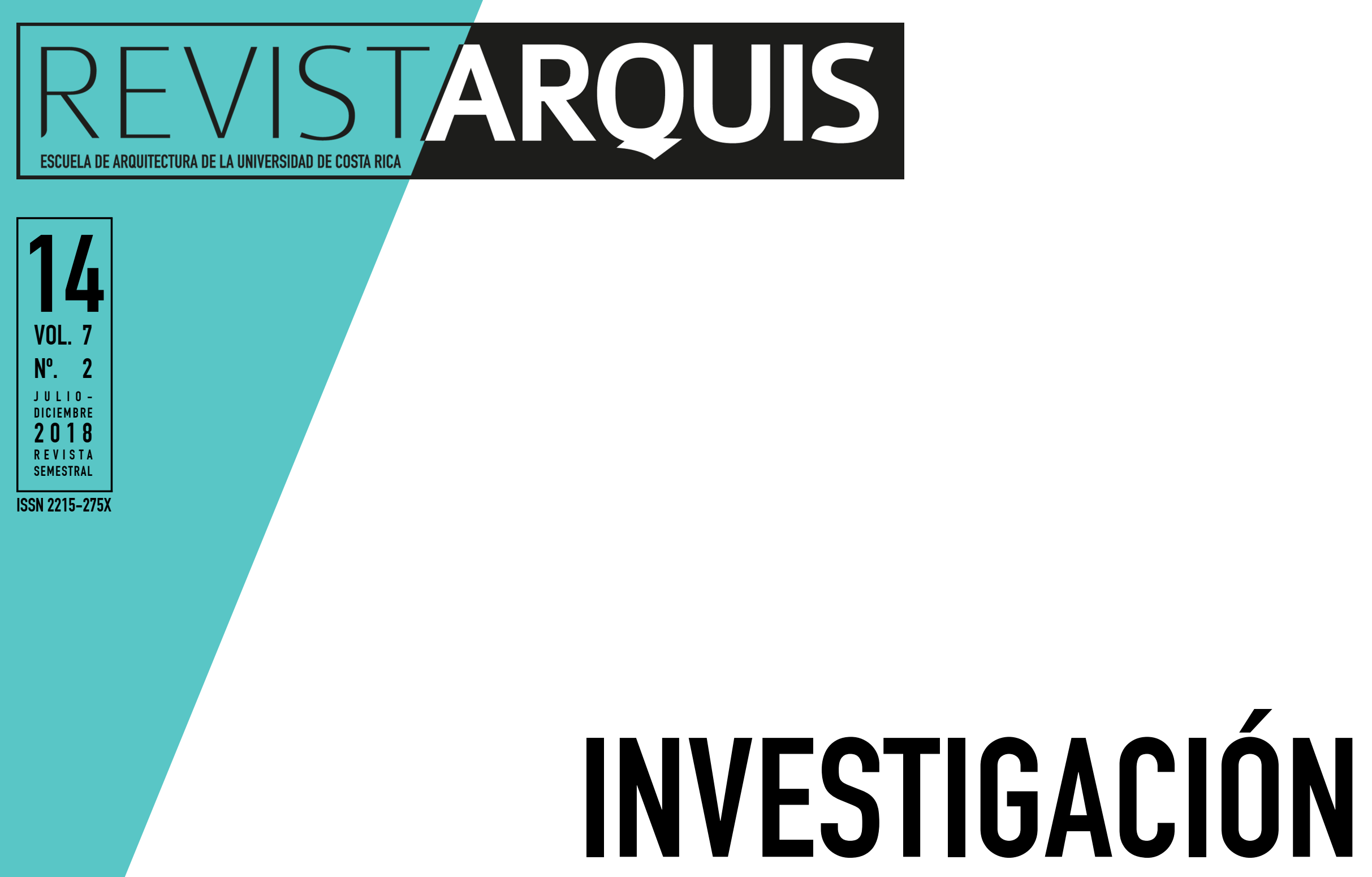

RESEARCH

Propuesta de vivienda incremental para la comunidad tsáchila a través métodos
participativos
Daniela Hidalgo Molina, Juan Diego Ponce y Gisella Raymond Cornejo. | 1-16

Injusticia espacial urbana en asentamientos informales

Milena Rincón Castellanos | 17-29 


\title{
Injusticia espacial urbana en asentamientos informales ${ }^{1}$
}

\author{
Milena Rincón Castellanos
}

Investigación

Invitada internacional

Colombia

Institución: Pontificia Universidad Javeriana

E-mail: milena.rincon@javeriana.edu.co

Recibido: 19 de octubre del 2017

Aprobado: 12 de mayo del 2018

\section{Milena Rincón Castellanos}

Profesora asistente de la Facultad de Arquitectura y Diseño de la Pontificia Universidad Javeriana.

\footnotetext{
1 Artículo derivado de la investigación científica titulada "Justicia espacial urbana: Conceptos y métodos de medición". La investigación fue apoyada por el Departamento de Arquitectura de la Facultad de Arquitectura y Diseño de la Pontificia Universidad Javeriana.
}

\begin{abstract}
Resumen:
Los asentamientos de origen informal en colombiana han surgido como una alternativa de acceso a vivienda para la población social y económicamente vulnerable frente a las limitadas oportunidades institucionales de acceso a una solución habitacional. Así, las víctimas del conflicto armado por desplazamiento forzado y la población que se encuentra en situación de pobreza han encontrado en esta modalidad de urbanización un refugio en la ciudad. Sin embargo, las diferentes modalidades de acceso al suelo marcado por procesos de urbanización irregular y de autoproducción de vivienda, desarrollados lejos del cumplimiento de la norma urbana, conllevaron a relacionar este tipo de asentamientos con una ciudad ilegal. Esta denominación conduce a la invisibilización de un conjunto de injusticias que las familias que allí habitan enfrentan permanentemente. Ante este escenario se adopta el concepto de justicia espacial propuesto en los años setenta con el movimiento intelectual denominado Geografía Radical, con el objetivo de explorar nuevas formas de aproximación a los asentamientos de origen informal que permita superar la idea confusa de entender lo legal como una acción de justicia. La exploración se realiza a partir de la revisión del conjunto de acciones políticas derivadas de las leyes diseñadas para garantizar el acceso a una vivienda a aquellas víctimas de desplazamiento forzado, producto del conflicto armado interno en Colombia, y la realidad observada a través de historias de vida. Finalmente, se observa que el diseño de las políticas públicas continúa siendo pensado desde una mirada utilitarista y que, por esta razón, las acciones de justicia se siguen midiendo en términos económicos y no en términos sociales.
\end{abstract}

Palabras clave: asentamientos de origen informal; derechos humanos; desplazamiento forzado en Colombia; justicia espacial; vivienda.

\section{Urban spatial injustice in informal settlements}

\begin{abstract}
:
The settlements of informal origin in Colombia emerged as an alternative to access housing for the socially and economically vulnerable population due to the limited institutional opportunities to obtain a solution. Thus, the victims of the armed conflict have found in this modality of urbanization a refuge in the city as a result of the forced displacement and the poverty. However, the different access modalities to the land relate this type of settlements with an illegal city due to the processes of irregular urbanization and self-production of housing developed far from the fulfillment of the urban norm. This denomination leads to an invisibilization of a set of injustices that the families who live there face off permanently. Given this scenario, the concept of space justice, which was proposed in the seventies, was adopted with the intellectual movement called Radical Geography, so it could be explored new approaches to settlements of informal origin that allowed to overcome the confused idea of understanding the legal as an action of justice. The exploration is carried out from the revision of the set of political actions derived from those aws designed to guarantee the access to housing to the victims of the forced displacement because of the internal armed conflict in Colombia, and the reality observed through life stories. Finally, it is observed that the design of public policies continues to be thought from a utilitarian perspective, and for this reason the actions of justice are still measured in economic terms and not in social terms.
\end{abstract}

Keywords: Unplanned city; Human rights, forced displacement in Colombia, space justice, housing. 


\section{Asentamientos informales}

iferentes estudios sobre los procesos de transformación urbana de las ciudades latinoamericanas han demostrado la tendencia de un crecimiento exponencial de su estructura física y de la población (Borsdorf, 2003; IDB y WB, 2010). Llama la atención respecto a esta dinámica la configuración espacial de los denominados asentamientos de origen informal, localizados principalmente en la periferia extrema de las ciudades.

Siguiendo a Molando (citado en Torres, 2007) modelos teóricos sobre la ciudad informal reconocen que es un espacio urbano que se configura en contraposición al orden urbano formal. Según el modelo de Turner (1965) "caracteriza los asentamientos informales como formas totalmente desordenadas y no sujetas a la regulación de las autoridades encargadas de establecer un régimen del uso de la tierra y la construcción de edificios". En esta definición Turner señala dos características constitutivas: lo no normativo y lo no formal del origen de los asentamientos informales, como una manifestación normal en un contexto de condiciones históricamente anómalas por la ausencia de alternativas institucionales o legales (citado en Torres, 2007, p. 66). Para Duhau (1998), lo que resulta importante comprender en este contexto es que es un orden espacial urbano alternativo que funciona como "la solución habitacional masiva al alcance de los sectores populares que ha consistido en las últimas décadas y consiste actualmente en el acceso al suelo a través de los procesos de urbanización irregular y la autoproducción de vivienda" (citado en Torres, 2009, p. 31).

Es cierto y evidente que los asentamientos de origen informal, porque se agrupan de manera irregular, se caracterizan por tener calles estrechas, carecer de adecuados servicios públicos colectivos e individuales, tener viviendas que generalmente no son adecuadas y albergan un grupo familiar extendido. Esta caracterización de la ciudad informal hecha por Turner, aún hoy se mantiene. Los barrios se van desarrollando de acuerdo con las posibilidades económicas, es decir, que entre menores sean los niveles de ingreso per cápita de los pobladores, tanto mayor serán los grados de hacinamiento y menor la calidad de vida que soporta. (Torres, 2009, p. 47)

Sin embargo, este orden urbano alternativo comprende un profundo orden social. Viviescas (citado en Puente, s.f.) plantea que "aunque el espacio urbano construido en estas condiciones está condenado a ser de muy baja calidad ambiental lo que se aprecia en ellos prefigura una gran riqueza de tipo espacial y arquitectónica... pero tiene la característica de lo potencial." (p. 20)

Frente a esta dualidad señalada por Viviescas, resulta fundamental entender que este potencial se configura a partir del proceso de decrecimiento y consolidación característicos de la ciudad informal y que, por lo tanto, resulta perentorio realizar una reflexión de estas dinámicas a la luz del concepto de [in]justicia espacial.

\section{Metodología}

La metodología de la investigación se construye a partir de la propuesta de análisis de política pública desarrollada por Humberto Restrepo (2006). La propuesta se centra en la compresión de la política pública a partir de dos dimensiones. La primera dimensión corresponde al núcleo, el cual guarda la sustancia política e ideológica, así como el conjunto de valores y principios. La segunda configura el conjunto de recursos, dispositivos, instituciones, normas y otros instrumentos a través de los cuales el núcleo de la política se materializa y se proyecta a la sociedad. En este sentido, se puede decir que las fracturas existentes entre estas dos dimensiones evidencian en una primera instancia una situación injusta.

$1 \quad$ Transformaciones no solamente desde el punto de vista de los impactos negativos por degradación de un espacio natural, sino referidas a la posibilidad de reconocer entre lo social, lo cultural y el espacio físico que se habita, eventos alternos o situaciones poco evidentes que puedan orientar una transición urbano-rural más sustentable en este borde tan particularmente caótico en Bogotá
A partir de lo anterior, el estudio se estructuró a partir de un diálogo entre las acciones señaladas en la ley, relacionadas principalmente con las garantías de acceso a una vivienda, y la realidad que deben enfrentar algunos hogares que han sido víctimas del conflicto armado interno en Colombia y que viven en la periferia extrema sur de Bogotá. De esta forma, la lectura de la ley se realizó a la luz de la historia de vida, lo cual permitió indagar las fracturas existentes entre las acciones definidas en las políticas públicas y los principios de dignidad que la misma política defiende. 
Para realizar lo anterior, se adoptó la historia de vida como técnica de investigación cualitativa que consiste en que una persona narre de manera profunda las experiencias de vida en función de la interpretación que ésta le haya dado a la misma y el significado que se tenga de una interacción social (Chárriez, 2012, p. 53).

Se realizaron entrevistas para reconstruir la historia de vida de las víctimas del conflicto que actualmente viven en un barrio de origen informal en Bogotá. Los temas centrales que se trataron apuntaron a tres situaciones cruciales. El primero hace referencia a la reconstrucción de los hechos del momento en que las personas fueron expulsadas de su tierra, en el segundo se indagó por el momento en que la familia llega a la ciudad $y$, finalmente, se indaga por los momentos de encuentro con el Estado para acceder a una vivienda.

En este artículo se contará la historia de vida de un caso de vivienda usada y subsidiada para un hogar, víctima por desplazamiento forzado. Se toma este caso en particular debido a que las acciones que se tomaron para garantizar la vivienda a la víctima son resultado de diálogos entre el sector formal y los habitantes de la ciudad informal. Esta situación se toma exclusivamente en este artículo, pues configura el punto de origen de la discusión sobre la injusticia espacial urbana que será tratado más adelante.

Para el desarrollo de la discusión, se tomarán referentes desde la filosofía y la geografía en relación con las nociones de justicia, para valorar que tan injusto resulta el caso señalado en este artículo.

2 De acuerdo con la Red Nacional de Información al servicio de las víctimas, por hecho victimizante se contempla: abandono o despojo forzado de tierras, actos terroristas, atentados, combates, amenazas, delitos contra la libertad y la integridad sexual, desaparición forzada, desplazamiento, homicidio, minas antipersonas, secuestro, tortura.

3 Artículo 1: Colombia es un Estado social de derecho, organizado en forma de República unitaria, descentralizada, con autonomía de sus entidades territoriales, democrática, participativa y pluralista, fundada en el respeto de la dignidad humana, en el trabajo y la solidaridad de las personas que la integran y en la prevalencia del interés general.

4 Todos los colombianos tienen derecho a vivienda digna. El Estado fijará las condiciones necesarias para hacer efectivo este derecho y promoverá planes de vivienda de interés social, sistemas adecuados de financiación a largo plazo y formas asociativas de ejecución de estos programas de vivienda.

$5 \quad$ Artículo 25:1. Toda persona tiene derecho a un nivel de vida adecuado que le asegure, así como a su familia, la salud y el bienestar, y en especial la alimentación, el vestido, la vivienda, la asistencia médica y los servicios sociales necesarios; tiene asimismo derecho a los seguros en caso de desempleo, enfermedad, invalidez, viudez, vejez y otros casos de pérdida de sus medios de subsistencia por circunstancias independientes de su voluntad. 2 (...).

$6 \quad$ Los Estados Partes en el presente Pacto reconocen el derecho de toda persona a un nivel de vida adecuado para sí y su familia, incluso alimentación, vestido y vivienda adecuados, y a una mejora continua de las condiciones de existencia. Los Estados Partes tomarán medidas apropiadas para asegurar la efectividad de este derecho, reconociendo a este efecto la importancia esencial de la cooperación internacional fundada en el libre consentimiento. (...).

\section{Derechos humanos y población desplazada}

El origen de los asentamientos informales, en el caso colombiano, se puede decir que han sido construidos bajo el manto de la injusticia en la medida que la población que allí reside no ha sido libre en la escogencia de este tipo de lugar para vivir. Un porcentaje importante de la población que habita en estos sectores han sido víctimas de la migración forzada ligada a la violencia que ha caracterizado el conflicto armado que ha vivido el país. Otro tanto, corresponde a los llamados pobres históricos que no han logrado superar su condición de pobreza. (Ceballos, Caquimbo y Rincón, 2014, p. 124)

De acuerdo con el Registro Único de Víctimas (RUV), para junio del 2017, Colombia registró 9.025.146 víctimas del conflicto armado por distintos hechos victimizantes ${ }^{2}$, de las cuales 7.219.471 corresponden a población víctima por desplazamiento forzado (Red Nacional de Información, 2017). En Bogotá, de acuerdo con la información de Alta Consejería para los Derechos de las Víctimas, la Paz y la Reconciliación recibida desde 1985, se han reportado alrededor de 639.000 víctimas, de las cuales 351.187 se quedaron a vivir en la capital y se han concentrado en diferentes partes de la ciudad, principalmente en las localidades de Ciudad Bolívar (44.145) Bosa (39.145), Kennedy (36.712), Suba (25.522) y San Cristóbal (20.219) (Ver mapa 1). De acuerdo con el registro único de víctimas (RUV), el $48 \%$ de ellas están en condición de pobreza y el $24 \%$ en pobreza extrema. En materia de educación, la mitad no terminó el bachillerato y la mayoría tiene tan solo tres grados de escolaridad.

Factores como el microtráfico, el desempleo, la educación y principalmente las dificultades en el acceso a vivienda son los principales problemas que las víctimas enfrentan en la ciudad. Esta situación pone en evidencia la importancia que adquiere la dimensión urbana como uno de los principales escenarios del conflicto colombiano, en particular con sus principales ciudades (Vidal, 2015).

En materia de derechos humanos, Colombia ha hecho cambios sustanciales que proclaman el respeto a los derechos de las personas, entre los que se cuenta el surgimiento de la Constitución Política de 1991, cimentada en el respeto a la dignidad humana como puede verse en el Artículo $1^{3} \mathrm{y}$, en materia de vivienda, su Artículo $51^{4}$ ratifica que todos los colombianos tienen derecho a una vivienda digna. En este contexto vale decir que la vivienda es reconocida dentro de los instrumentos jurídicos sobre los derechos humanos como un componente fundamental para el desarrollo de una adecuada calidad de vida y una existencia con dignidad. Ejemplo de ello son la Declaración Universal de los Derechos Humanos de 1948, en particular su Artículo $25^{5}$ y el Pacto Internacional de Derechos Económicos, Sociales y Culturales (Pidesc) de 1966, en especial su Artículo $11^{6}$, entre otros. 
Mapa 1. Ubicación de víctimas por Localidades en Bogotá

Fuente: Elaboración propia a partir de Rivera, M y Dulce, L. (2017). Datos suministrados por la Unidad de atención y reparación a las víctimas, Subdirección Red Nacional de Información.
$7 \quad$ Ley 1448 de 2011. "Por la cual se dictan medidas de atención, asistencia y reparación integral a las víctimas del conflicto armado interno y se dictan otras disposiciones".

$8 \quad$ Art. 3: Vale la pena aclarar que, según la ley, se consideran víctimas, aquellas personas que individual o colectivamente hayan sufrido un daño por hechos ocurridos a partir del $1^{\circ}$ de enero de 1985, como consecuencia de infracciones al Derecho Internacional Humanitario o de violaciones graves y manifiestas a las normas internacionales de Derechos Humanos, ocurridas con ocasión del conflicto armado interno.

$9 \quad$ Ley 1448 de 2011. Artículo $8^{\circ}$. JUSTICIA TRANSICIONAL. Entiéndase por justicia transicional los diferentes procesos y mecanismos judiciales o extrajudiciales asociados con los intentos de la sociedad por garantizar que los responsables de las violaciones contempladas en el artículo $3^{\circ}$ de la presente ley, rindan cuentas de sus actos, se satisfagan los derechos a la justicia, la verdad y la reparación integral a las víctimas, se lleven a cabo las reformas institucionales necesarias para la no repetición de los hechos y la desarticulación de las estructuras armadas ilegales, con el fin último de lograr la reconciliación nacional y la paz duradera y sostenible.

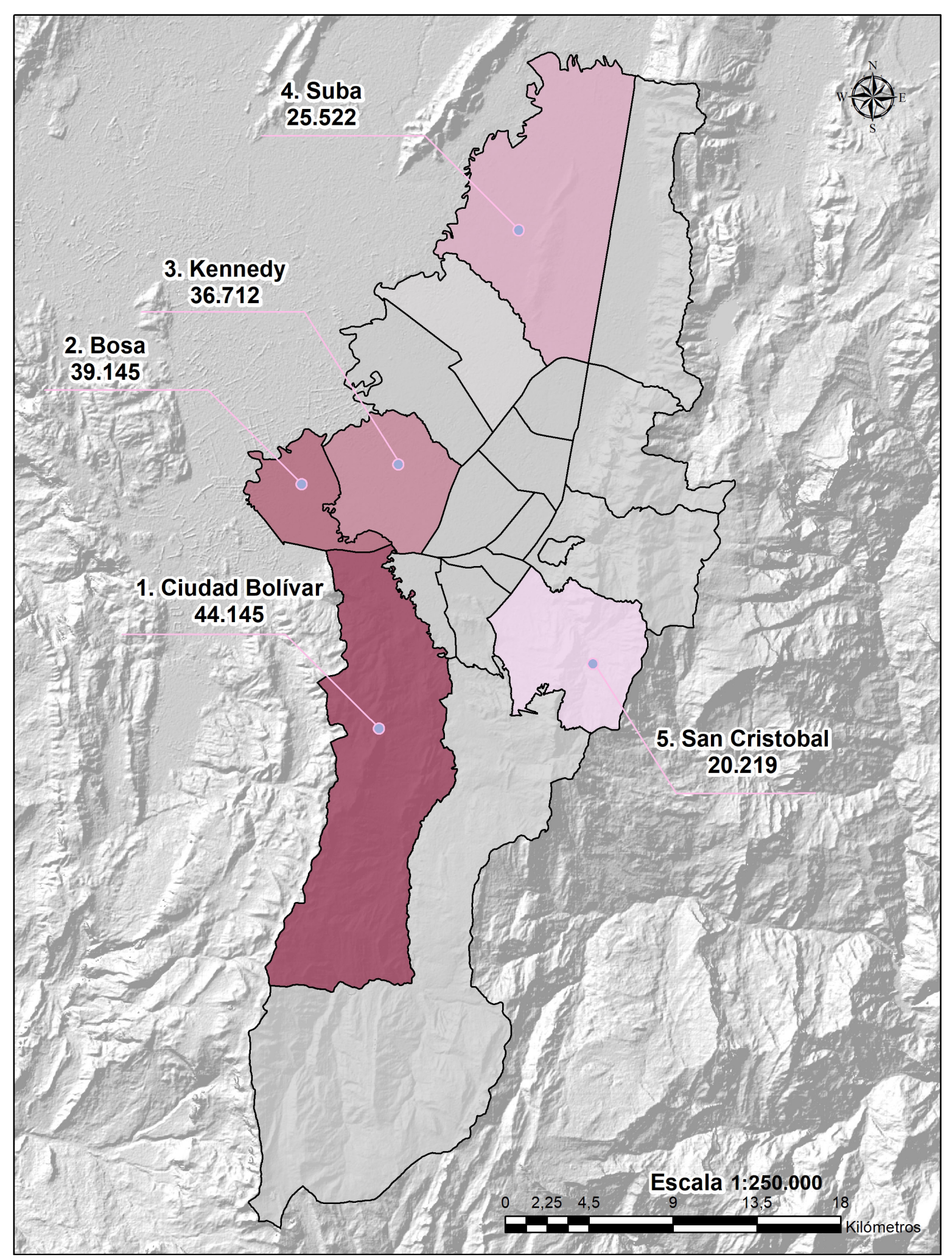

Otro cambio reconocido es la creación de la Defensoría del Pueblo en la estructura del Gobierno Nacional. Su principal misión es impulsar la efectividad de los derechos humanos de los habitantes del territorio nacional y de los colombianos en el exterior en el marco del Estado Social de Derecho democrático, participativo y pluralista.

El programa de Gobierno "Todos por un nuevo país 2014-2018", tiene entre sus ejes, el diseño y la implementación de una política pública orientada a la reparación integral de las víctimas del conflicto armado interno en Colombia, el fortalecimiento del aparato judicial y administrativo, y la generación de condiciones propicias para promover y consolidar la paz y la reconciliación nacional. Lo anterior da como resultado la creación de la Ley de Víctimas y Restitución de Tierras (Ley N 1448,2011$)^{7}$, la cual constituye para el país un marco legal sin precedentes para recomponer el tejido social, adoptando medidas efectivas a favor de las personas que han sufrido las consecuencias del conflicto armado ${ }^{8}$.

Esta ley tiene por objeto establecer un conjunto de medidas judiciales, administrativas, sociales y económicas, individuales y colectivas, en beneficio de las víctimas de las violaciones, dentro de un marco de justicia transicional ${ }^{9}$ que posibiliten hacer efectivo el goce de sus derechos a la verdad, la justicia y la reparación con garantía de no repetición, de modo que se reconozca su condición de víctimas y se dignifique a través de la materialización de sus derechos constitucionales (Ley N 1448, 2011).

Si bien la Ley 1448 señala distintos aspectos que deben ser prioritarios para la reparación de las víctimas, entre ellos la vivienda, no plantea una estrategia específica para garantizar el acceso a la casa de habitación, la postura que toma es unirse a las acciones de la política de vivienda nacional y a las que correspondan en cada municipio. 
Así, el acceso a la vivienda se garantiza a través del Programa Gobierno Nacional de Vivienda Gratuita, el cual se crea con el objetivo de entregar viviendas de interés prioritario, a título de subsidio en especie a la población vulnerable (Decreto 1921, 2012). La cuestión aquí es que por población vulnerable se entiende: a) que esté vinculada a programas sociales del Estado que tengan por objeto la superación de la pobreza extrema o que se encuentre dentro del rango de pobreza extrema; b) que esté en situación de desplazamiento; c) que haya sido afectada por desastres naturales, calamidades públicas o emergencias; y/o d) que se encuentre habitando en zonas de alto riesgo no mitigable. Dentro de la población en estas condiciones, se dará prioridad a las mujeres y hombres cabeza de hogar, personas en situación de discapacidad y adultos mayores (Ley N¹537, 2012).

La realidad es que algunas personas pueden acceder al programa del Gobierno Nacional, otros acceden a una parte del subsidio familiar de vivienda para acceder a una vivienda usada, y otros deciden, por distintas razones, continuar la búsqueda de una vivienda adecuada. Entre estas razones está que la vivienda que reciben no configura elementos espaciales que les permita identificarse con sus raíces culturales, o que no encuentran opciones para resolver el tema de ingresos, o sencillamente no tienen conocimiento de tales programas.

\section{Injusticia espacial urbana}

En esta sección del texto se pretende esbozar la situación de injusticia espacial urbana presente en el caso ya mencionado, teniendo en cuenta los postulados desde la filosofía y la geografía en relación con la definición del concepto de justicia, y con el ánimo de encontrar elementos para realizar una valoración de que tan injusta puede resultar una determinada situación.

Al indagar por las acciones que permitan la construcción de una sociedad justa, es importante preguntar por cómo se distribuyen los elementos que representan una vida digna: ingresos y patrimonio, deberes y derechos, poderes y oportunidades. Pues una sociedad justa distribuye esos bienes como es debido, es decir, da a cada uno lo suyo. En este sentido se distinguen tres formas de abordar la distribución de bienes: según el bienestar, la libertad y la virtud (Sandel, 2014).

En el pensamiento de la filosofía política, la tradición clásica sobre la concepción del término de justicia tiene sus raíces en el contrato social centrado en la cooperación social, siendo así, la solidaridad y beneficio mutuo los principales derroteros para el logro de una sociedad justa. En complemento, vale mencionar que las relaciones entre Estados, al igual que el resto de los asuntos humanos, están reguladas por el derecho natural, lo que implica unas leyes morales que imponen límites normativos a los Estados. En este sentido, la dignidad del ser humano se entiende como el fin último de las leyes (Nussbaum, 2007).

En esta línea, el modelo de pensamiento iniciado por Thomas Hobbes ${ }^{10}$ da origen a un enfoque contractualista de la justicia, el cual se centra en la búsqueda de la naturaleza de lo justo. Esto da lugar a la idea de justicia basada en el institucionalismo trascendental, puesto que hace referencia a la creación de una sociedad equitativa a partir de la definición de instituciones perfectamente justas. Lo anterior presenta limitaciones, por una parte, la búsqueda de la justicia absoluta impide reflexionar en torno a cómo lograr situaciones menos injustas y, por otra parte, las acciones estructuradas desde un esquema institucional definido a partir de esquemas organizacionales que implican regulaciones y reglas de conducta. Sin embargo, lo que desencadena es un desconocimiento total de las verdaderas y reales interacciones de las personas (Sen, 2010).

10 El modelo de pensamiento contractualista fue iniciado por Thomas Hobbes y continuado por John Locke, Jean Jackes Rousseau y Immanuel Kant.
En este contexto es importante mencionar el enfoque económico-utilitaristas, cuya idea central es maximizar el bienestar en una sociedad de mercado como la nuestra, a partir del aumento de la prosperidad, del nivel de vida y de los estímulos para el crecimiento económico. Por tanto, se entiende que la utilidad maximiza la felicidad. En consecuencia, una medida de bienestar termina concretándose con la asignación de un valor monetario a la vida humana (Sandel, 2014). Así, el principal criterio de 
medición consiste en clasificar los países en función del Producto Interno Bruto (PIB), por lo que este enfoque no resulta iluminador en medida que no plantea la distribución de los ingresos y la riqueza, adicionalmente, no da pistas de cuáles son los elementos esenciales para la vida humana (Nussbaum, 2007).

La obra de Rawls ${ }^{11}$ se reconoce como una de las contribuciones más importantes al estudio de la justicia, su enfoque está centrado en comprender la justicia como equidad. A pesar de que este planteamiento ha recibido muchas críticas, se rescatan dos principios que continúan siendo influyentes para la formulación de una teoría sobre la justicia: el primero es la prioridad de la libertad, y el segundo, la igualdad de oportunidades y la equidad en la distribución de los recursos, denominado también principio de diferencia. El primero se refiere a la libertad que realmente tienen las personas para escoger entre diferentes estilos y modos de vida. El principio de diferencia busca que las personas que están en condiciones precarias cuenten con lo mínimo para vivir. En este sentido, Rawls define una lista de bienes primarios como medio de evaluación de las oportunidades que la gente tiene a través de los medios que posee, sin embargo, esta aproximación no contempla las posibles variaciones que pueden existir de una persona a otra. En contraste con el institucionalismo trascendental, está el enfoque denominado realizaciones sociales ${ }^{12}$, el cual se centra en la comparación de sociedades en lugar de la búsqueda trascendental de una sociedad totalmente justa, pues este enfoque se interesa por la eliminación de la injusticia manifiesta en el mundo (Sen, 2010, p. 92- 93.)

Lo anterior motiva la propuesta de Sen y Nussbaum de convertir los bienes primarios en un enfoque de capacidades, que implica comprender las oportunidades no desde lo que se posee, sino desde la habilidad efectiva de las personas para optar por diferentes tipos de vida a su alcance Adicionalmente, es una reacción a la postura utilitarista, que busca una construcción de una teoría de derechos básicos de los seres humanos que deben ser respetados y aplicados por los gobiernos como requisito mínimo del respeto hacia la dignidad humana (Sen, 2010).

En este sentido, Nussbaum propone una lista abierta que describe derechos sociales mínimos que permiten visualizar lo que sería una vida desprovista de los mismos y, por tanto, no correspondería a una vida digna. Estos serían: la vida; la salud física; la integridad física; los sentidos, la imaginación y el pensamiento; las emociones; la razón práctica; la afiliación (capacidad de vivir con y para los otros); otras especies; el juego; y el control sobre el propio entorno.

Desde la perspectiva geográfica, se señala que la tradición de los estudios en esta línea ha estado marcada por la defensa de las necesidades sociales en la medida que se ha preocupado por entender la relaciones entre el hombre y la naturaleza, evolucionando según los cambios sociales. En este sentido, para combatir el individualismo, la competitividad y segregación espacial que el capitalismo imprime en la ciudad, se acogen conceptos que conservan en su significado la lucha por la justicia en la ciudad. De esta manera, en los años setenta surge el concepto de justicia espacial, el cual tiene sus raíces con el movimiento intelectual denominado Geografía Radical. Este movimiento encontró en el marxismo el sustento teórico para su actitud de ciencia crítica, comprometida políticamente con la transformación revolucionaria de la sociedad capitalista (Delgado, 2003).

Para Reynaud (citado en Moreno, 2006, p. 136) la justicia socio-espacial es "el conjunto de medios utilizados por los poderes públicos para atenuar las desigualdades entre las clases socio-espaciales" La justicia ideal consistiría en la supresión de todas las desigualdades, lo que aplicado al plano geográfico significa que se logra igualar las oportunidades y los resultados de los ciudadanos.

Soja (2010) trata de explorar la idea de justicia espacial como un concepto teórico, siendo el punto de focalización para el análisis empírico y objetivo de las acciones políticas y sociales, entendiendo que la idea de justicia, en cualquier definición, tiene implicaciones geográficas y de expresión espacial, más allá de una serie de atributos físicos que puedan ser mapeados. Así, "el reconocimiento de que el espacio importa ofrece nuevas pistas, no sólo de cómo la injusticia es producida a través del espacio, sino también cómo el análisis espacial de la injusticia puede avanzar en la lucha por justicia social, informando las demandas concretas y las prácticas que visibilizan dichas demandas" (Citado en Link, 2011, p. 173). 
De acuerdo con Harvey (1977), el concepto de justicia aplicado a situaciones geográficas puede ser entendido a partir de la organización espacial y el modelo de inversión regional que deben cubrir las necesidades de la población. De tal manera que se deben establecer métodos socialmente justos para determinar y medir las necesidades. Las diferencias entre las necesidades y las asignaciones proporcionan una evaluación inicial de la injusticia espacial. De igual forma, debe proporcionar beneficios adicionales en forma de satisfacción de necesidades principalmente, en un segundo lugar el aumento del volumen de la producción y, finalmente, las desviaciones dentro del modelo de inversión territorial pueden ser toleradas si tienen como finalidad superar dificultades ambientales. Plantea que una estructura es completamente justa cuando las ventajas de los más afortunados promocionan el bienestar de los menos afortunados. De tal manera, el problema geográfico consiste en idear una forma de organización espacial que maximice las posibilidades de las regiones menos afortunadas. Por lo tanto, es necesario precisar medios socialmente justos para la delimitación de territorios y un medio justo para asignar los recursos a ellos.

En esencia, el concepto de justicia espacial busca adoptar los aportes teóricos de la filosofía política sobre justicia con una dimensión nueva, la espacial, a través del vehículo de la ciencia geográfica (Moreno, 2006).

\section{Vivienda usada y subsidiada por el Estado a una víctima por desplazamiento forzado.}

A partir de lo expuesto, se toma como referencia una de las acciones derivadas de la política pública en relación con la población víctima por desplazamiento forzado, (Ley $\mathrm{N}^{\circ}$ 1448, 2011). De acuerdo con la ley, las víctimas tienen derecho a la verdad, justicia y reparación ${ }^{13}$, por lo tanto, las autoridades competentes deberán adoptar medidas de protección integral. En este contexto se entiende como el esclarecimiento de los hechos, la identificación de los responsables, y su respectiva sanción. De esta manera, se contará la historia de vida de una familia víctima de violencia con el fin de comprender la realidad socio espacial de la misma a la luz de los planteamientos de justicia señalados en el capítulo anterior.

La situación de desventaja social y económica que muchas familias colombianas han enfrentado en las zonas rurales tiene que ver con: la alta concentración de la propiedad; el uso ineficiente de suelos; los altos índices de pobreza; la institucionalidad rural inconsistente; la destrucción de los recursos naturales; la escasa participación de los pobladores rurales en los sistemas de decisión, la adquisición de tierras con fines ilícitos, entre otras (Franco y De los Ríos, 2011)

Este es el caso de Carlos Navas ${ }^{14}$, un ciudadano colombiano de 59 años y oriundo de Puerto López, municipio del departamento de Córdoba, Colombia. Don Carlos y su familia, acostumbrados a trabajar en cultivos de arroz, maíz, yuca, plátano, cría de cerdos y ganado, se vieron obligados a cultivar coca, ya que los grupos armados al margen de la ley infundían miedo y falsas ideas en los campesinos para garantizar la proliferación de este tipo de cultivo y, como él dice:

Todas las fincas, todo era coca, todo el mundo no hablaba sino de coca y de millonadas de pesos y yo sólo deseaba cultivar la tierra. Y todo el mundo me decía no, se va a fregar su cosecha, usted para llevar un quintal de maíz al pueblo necesita un cosalote, en cambio para llevar cinco libras de coca, las lleva en un bolso y no pasa nada y del pueblo trae la yuca trae el plátano trae todo. (C. Navas, comunicación personal, 2016)

Para cultivar la coca, las familias deben invertir su esfuerzo económico y su tiempo. Tumbar los rastrojos, buscar las semillas, hacer los semilleros, sembrar la planta, comprar abonos, fertilizarla y trabajarla son las nuevas tareas que deben aprender. Después de la tercera cosecha o "raspa", como don Carlos le dice, aparecen los grupos guerrilleros para cobrar la vacuna. Don Carlos debía entregar el $20 \%$ de lo producido, como él dice:

De la cosecha de coca que yo cogí y recogí, si me dan por ahí unas cinco libras yo tengo que darles a ellos una libra y a mí me quedan cuatro, si da diez libras yo tengo que darles a ellos un kilo y yo quedarme con ocho libras. (C. Navas, comunicación personal, 2016) 
15 Este término se refiere a la acción de recoger la hoja de coca. Consiste en retirar las hojas deslizando sus manos por cada tallo de la mata de coca.

\section{Término coloquial usado para referirse a} una zona para sembrar su propio cultivo.

\section{$17 \quad$ Ley 1448, artículo 61. Las personas} pueden ser declaradas víctimas del conflicto armado por desplazamiento siempre y cuando estos hechos hubiesen ocurrido a partir del $1^{\circ} \mathrm{de}$ enero de 1985, y no se encuentre registrada en el Registro Único de Población Desplazada.
Una de las consecuencias de esta situación es la deserción escolar, pues los niños se desarrollan y crecen en un falso escenario, como dice don Carlos:

El niño al ver cómo funciona el negocio de la coca prefiere ganar un millón, seiscientos mil, setecientos mil pesos, entonces el niño deja el estudio por irse a raspar ${ }^{15}$ o por hacer su tajo ${ }^{16}$ también. (C. Navas, comunicación personal, 2016)

Sin embargo, el cultivo de coca implica altos costos para un campesino y, en muchos casos, no alcanza para pagar la mano de obra que se requiere o los insumos que se necesitan para iniciar un nuevo cultivo. Estas dificultades generan grandes inconvenientes para estar al día con la vacuna que deben pagar. Cuando esto sucede, la familia recibe una "boleta" por parte del grupo guerrillero, esto significa una cita con la muerte. Don Carlos explica que:

El que sube allá a una cosa de esas, es rarito el que baja. Esa tarde no comimos en la casa, mi papá llorando, ella llorando porque eso es delicado y que uno vaya para la montaña, rarito el que regresa. (C. Navas, comunicación personal, 2016)

Afortunadamente, don Carlos regresó de ese aparente viaje oscuro, sin embargo, las condiciones en las que se encontraba no eran favorables y la única opción que quedaba era abandonar su tierra.

De acuerdo con la Ley 1448, las personas víctimas de desplazamiento forzado deberán rendir una declaración ante cualquiera de las instituciones que integran el Ministerio Público dentro de los dos años siguientes a la ocurrencia del hecho que dio origen al desplazamiento ${ }^{17}$. De esta forma, la primera acción de atención a las víctimas se concreta en una carta que reconoce a las personas como víctimas.

Para las familias desplazadas esta carta significa un pasaje de abordo a un viaje con esperanza. Es de esta manera que don Carlos llega a Bogotá, a un barrio localizado en Usme, en la periferia extrema sur de Bogotá (Figura 1). Una vez allí busca las ayudas que ofrece el Estado a la población desplazada para acceder a una vivienda, y como él le dijo a uno de los funcionarios que lo atendió:

Quiero una vivienda porque tengo hijos y soy del campo, estoy aquí en Bogotá y yo no sé nada de trabajo, no tengo plata para comprar una casa y lo mío quedó todo por allá. (C. Navas, comunicación personal, 2016)

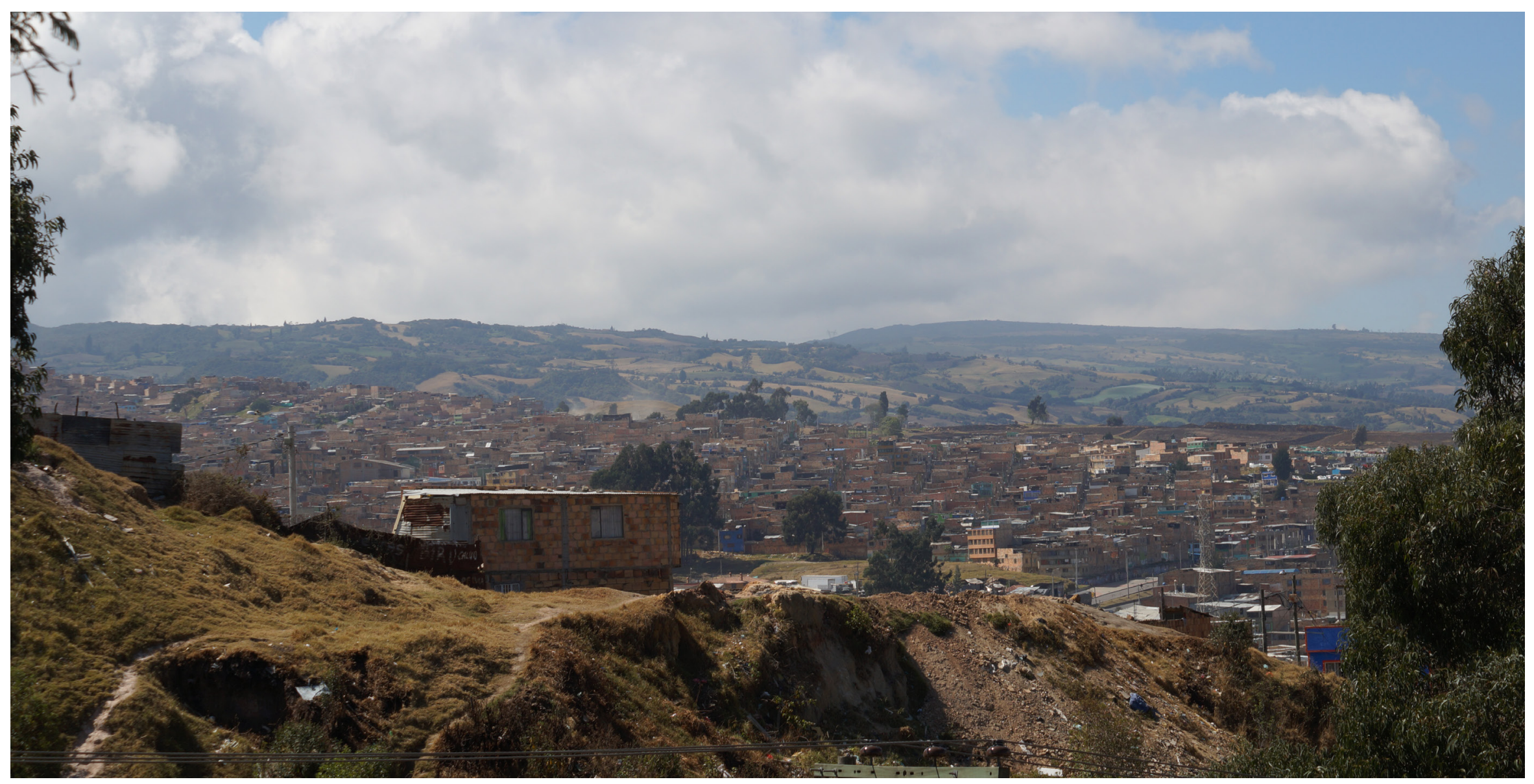

Figura 1. Asentamiento Informal. Localidad de Usme, Bogotá.

Fuente: Milena Rincon Castellanos, 2016. 
18 Ley 1448, artículo 6. Etapas de la atención humanitaria. Se establecen tres fases 0 etapas para la atención humanitaria de las víctimas de desplazamiento forzado: 1. Atención Inmediata; 2. Atención Humanitaria de Emergencia; y 3. Atención Humanitaria de Transición.

Figura 2. izquierda arriba. Vivienda usada en Usme Subsidiada por el Estado.

Fuente: Milena Rincon Castellanos, 2016.

Figura 3. izquierda abajo. Interior de la vivienda. Fuente: Milena Rincon Castellanos, 2016.

Figura 4. derecha. Interior de la vivienda. Fuente: Milena Rincon Castellanos, 2016.
En dicha ley está estipulada una ayuda humanitaria ${ }^{18}$ y las medidas de restitución en materia de vivienda. Tal como se señala en el art. 123: "las víctimas cuyas viviendas hayan sido afectadas por despojo, abandono, pérdida o menóscabo, tendrán prioridad y acceso preferente a programas de subsidios de vivienda en las modalidades de mejoramiento, construcción en sitio propio y adquisición de vivienda establecidos por el Estado. Lo anterior, sin perjuicio de que el victimario sea condenado a la construcción, reconstrucción o indemnización".

En Colombia, la política de vivienda dirigida a la población vulnerable económicamente está definida principalmente por un valor económico. De conformidad con las leyes 3 de 1991, 1469 de 2001 y lo señalado en el sitio WEB del Ministerio de Vivienda del Gobierno Nacional, la Vivienda de Interés Social no puede exceder los 135 salarios mínimos mensuales legales vigentes (135 SMLMV) y la Vivienda de Interés Prioritario (VIP), los setenta salarios mínimos mensuales legales vigentes (70 SMLMV). Esto resulta contradictorio con el objetivo de fijar condiciones necesarias para garantizar el derecho a una vivienda adecuada, ya que el valor económico definido para la VIS impacta en el diseño de estas. En esta medida, los proyectos de VIS han sacrificado tanto el espacio al interior de la vivienda, como los acabados y la localización, con el fin de poder cumplir con la norma y, por lo tanto, queda comprometida la habitabilidad de los hogares, tal como se ha señalado por diferentes autores.

En este sentido, la familia de igual forma debe cumplir con los requisitos establecidos por la política de vivienda para poder postularse a la ayuda humanitaria que dicha ley menciona.

Llenamos los formularios, duramos como tres años y yo pidiéndole a Dios, entonces, salió el subsidio que era de $\$ 8.950 .000$ (...) Cuándo recibí el segundo subsidio por $\$ 10.000 .000$, me dijeron, bueno ya puede seguir buscando casa. (C. Navas, comunicación personal, 2016)
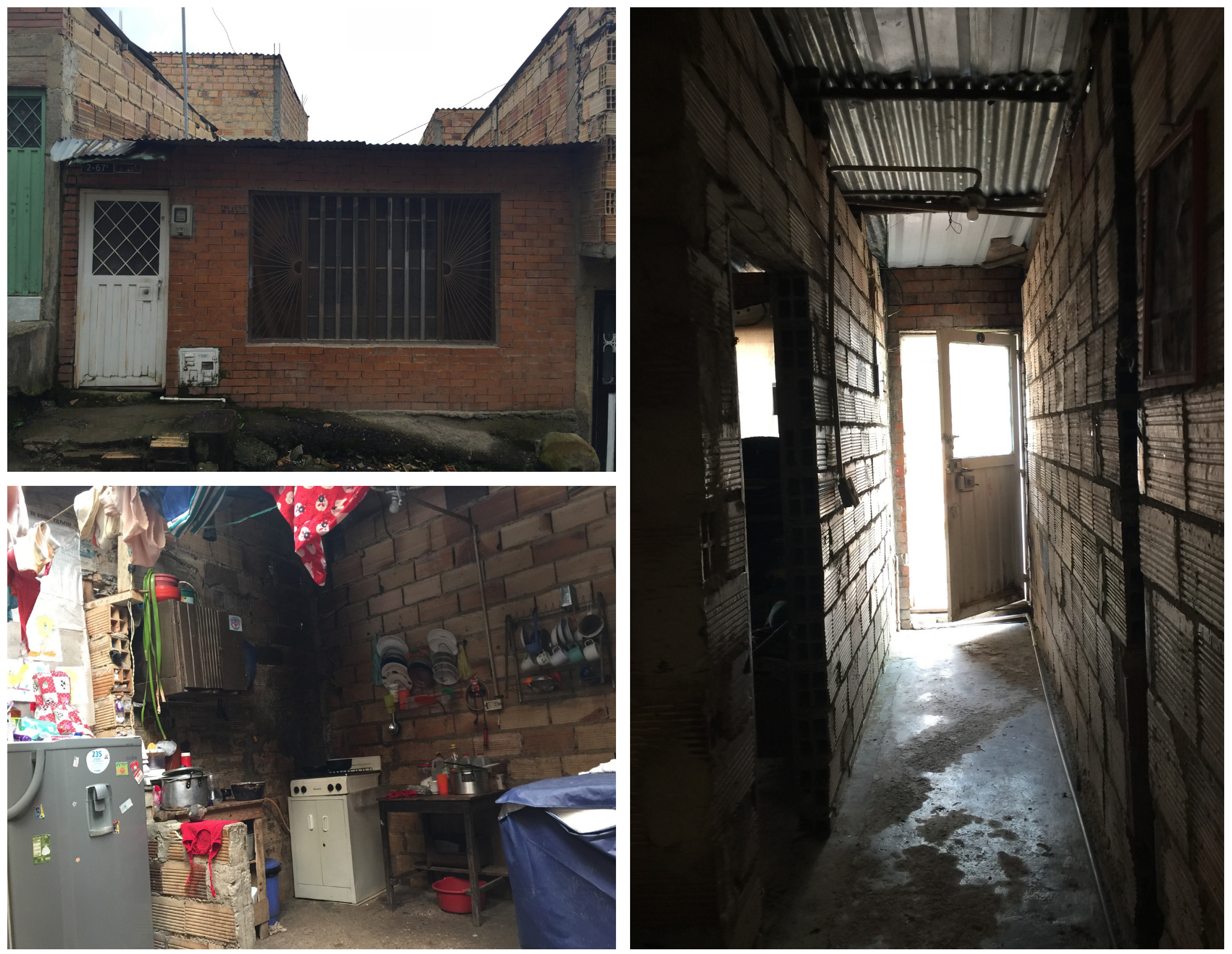
Las personas que habitan en un asentamiento informal se encuentran en desventaja social, en especial las víctimas por desplazamiento forzado en Colombia. Pues, a pesar de todo el esfuerzo que hacen día a día para superar su condición de pobreza, no es suficiente para garantizar el acceso a una vivienda, a un entorno sano, a educación, a salud, a un empleo, entre otros servicios urbanos.

Los hogares deben cambiar su estilo de vida de un día para otro, deben enfrentar los desafíos que implican vivir en una parte de la ciudad que ofrece reducidas oportunidades de superación, especialmente para la población joven. Si en el campo el principal temor es que un hijo se vaya a la guerrilla, en la ciudad se teme que el hijo caiga en drogas o pandillas.

(...) trabajar con la construcción por ahí de ayudante y esas cosas, y trabajaba por ahí de vigilante. En todo caso yo empecé a buscar la comida. (C. Navas, comunicación personal, 2016)

(...) también con mi hijo sufrí porque cuando llegamos acá al barrio, yo trabajando por allá y como decía mi mamá, <<El día me llevaba y la noche me traía >> El muchacho quedaba acá solo, con sus malas amistades. (C. Navas, comunicación personal, 2016)

En la ciudad informal se percibe una clara situación de injusticia, en donde las reducidas oportunidades de acceso a la educación, el aumento de la probabilidad de adquirir una enfermedad física o mental, el proceso de adaptación a la ciudad de personas que vienen de trabajar el campo y todo lo que esta condición puede desencadenar, configuran una esfera que pareciera que estuviera invisible, pero que condensa el resultado de las acciones políticas, sociales y económicas en el país.

De tal manera, la persona es expulsada de su tierra por acciones de coerción, luego entra en contacto con el Estado con la esperanza de que tomará parte de un conjunto de acciones justas; sin embargo, es situado en una parte de la ciudad que recibe todas las connotaciones negativas de ilegalidad, clandestinidad y que, por este hecho, las acciones del Estado no pueden llegar.

\section{Conclusiones}

La configuración de la ciudad informal es resultado de un conjunto de injusticias, sin embargo, ha jugado un papel muy importante en la ciudad, pues el gran esfuerzo que las personas han venido realizando en el proceso de consolidación ha permitido que de alguna manera las víctimas encuentren un hogar. No obstante, este proceso de configuración en medio de condiciones precarias ha generado miradas discriminatorias por parte de quienes no habitan allí. Así, al dirigir la mirada a la ciudad informal es muy fácil caer en un sentimiento de injusticia, pero es triste que la sociedad se haya acostumbrado a vivir con ella y por eso muchas dejan de serlo.

Las condiciones de discriminación espacial que implican no aceptar las diferencias del otro, no valorar su condición étnica o su situación socioeconómica, condenan a grupos sociales a organizarse en sus propias colonias o asentamientos humanos con el deseo de proteger su identidad y valores culturales para satisfacer sus necesidades básicas. Desafortunadamente, estos grupos sociales han vivido bajo el manto de la injusticia, pues terminan ocupando zonas de discriminación espacial, es decir, partes del área urbana que no cumplen con condiciones físicas y espaciales adecuadas que permitan lograr mejores condiciones de vida. Una consecuencia de este proceso de configuración espacial es la alta concentración de población y la condena que vivir en una situación de pobreza (Raffestin, 2011).

Las acciones que se definen para orientar las intervenciones en la ciudad informal están fundamentadas en los principios clásicos de la justicia, la cuales tienen serias limitaciones para lograr una sociedad justa, de tal manera que el diseño de acciones y políticas innovadoras que permitan la reducción de estas condiciones injustas continúan siendo negadas.

Así, desde la mirada desde el institucionalismo trascendental, la ciudad informal es considerada y señalada como un escenario de ilegalidad, hecho que ha limitado ver esta parte de la ciudad como un componente sustancial en toda la estructura urbana. 
En consecuencia, las intervenciones distritales en esta parte de la ciudad terminan siendo obras puntuales de regulación urbana (mejoramiento urbano) que no apuntan a una reestructuración que brinde mayores oportunidades a las personas para acceder a más y mejores servicios urbanos.

En relación con los planteamientos del enfoque utilitarista, a pesar de las serias limitaciones que este presenta, continúa siendo una construcción teórica muy influyente que domina los debates sobre el diseño de políticas públicas, especialmente en materia de vivienda. La discusión entre una mirada utilitarista y de bienestar pareciera que ya se hubiera agotado, y que la inclusión de temas de derechos humanos a la política de vivienda hubiera resuelto la situación. Sin embargo, las políticas tienden a medir los valores humanos en una sola escala, es decir, por la cantidad o la intensidad de felicidad o de placer que algo produce, sin importar que tan indigno puede resultar. De tal manera que las acciones concretas orientadas a la maximización del bienestar están dadas en función de un valor monetario para la vida humana. Es así como tenemos una definición de vivienda social expresada en términos económicos, un subsidio económico que no corresponde con las capacidades reales de las personas.

En relación con el principio de libertad se puede decir que la historia de un ser humano víctima por desplazamiento forzado evidencia una forma de coerción que representa una privación de la libertad humana. En este sentido, la ciudad informal está marcada por la constante privación de libertades humanas, por una parte, las personas terminan siendo obligadas a vivir bajo una estructura urbana que según Mill (citado en Sandel, 2014 , p. 17) se puede interpretar como grandes limitaciones para alcanzar el más elevado fin de la vida humana; por otra parte, las condiciones socioeconómicas limitan las expectativas de las personas, condenándolas a un gran esfuerzo que al final ofrece con pocos resultados, o en casos más extremos, llevar una vida tan solo para esperar la muerte. $Y$ con respecto al principio de diferencia que busca mejorar las condiciones de vida de las personas en desventaja social, se puede afirmar que la persona en la ciudad informal busca resolver de alguna manera las formas de satisfacer sus necesidades básicas, aunque está aislado de las acciones de la política. Lo anterior hace un llamado sobre la importancia de las acciones justas en los esquemas sociales determinados por las instituciones.

En palabras de Sen (2010, p. 34), la cuestión que subyace aquí es que, frente al conjunto de injusticias, por una parte, hay argumentos que terminan anulando a aquellos que realmente evidencian una situación injusta, evidenciando que la ilegalidad está por encima de la ciudad informal, ignorando el estilo de vida que realmente las personas pueden vivir. Por otra parte, parece que resulta necesario llegar primero a un acuerdo sobre un tipo de censura específica con miras a un consenso razonado para que una situación injusta sea rectificada.

Lo anterior demuestra las fracturas existentes entre el contenido esencial de la Política Pública de Vivienda y las acciones que se realizan para ponerla en práctica. Es una evidencia sólida de la injusticia espacial urbana. De tal forma, es necesario pensar en estrategias de acceso y de calidad de la vivienda orientadas al desarrollo de las capacidades de las familias, sin dejar de lado el respaldo económico que una intervención de esta magnitud requiere. En palabras de Sen (2010, p. 263-264) se trata de pasar de la concentración de los medios de vida a la concentración de oportunidades reales para vivir.

El problema con la política urbana es que no se centra en la especialidad de los problemas ni en las dinámicas y procesos espaciales que los producen y reproducen, si no que se enfoca en los problemas en el espacio, dando como resultado la delimitación de ciertas áreas en la ciudad como ha sucedido con la ciudad informal, una problemática que se asocia más a una condición de ilegalidad dejando de lado las realidades de las personas que viven allí. Esto da como resultado la identificación de territorios en desventaja social, pero la asignación de recursos para estos no corresponde con las necesidades que allí se presentan, desencadenando una fijación de identidades en el espacio que terminan por estigmatizar a quienes habitan las zonas reconocidas como de mayor vulnerabilidad (Dike citado en Cifuentes, 2007). 
En este sentido, es perentorio la formulación de una política pública dirigida a la ciudad informal que contemple nuevos principios de justicia. En esta línea, es importante resaltar que la justicia no se trata solamente del cumplimiento de la norma, si no que se trata de algo superior y de todo aquello que protege la vida de las personas. Así, el sentimiento de justicia debe estar basado en la articulación plena de la esencia de los derechos humanos y sus libertades con las acciones que se derivan de la política pública, puesto que no se trata de lograr una ciudad totalmente justa, si no que se trata de eliminar o mitigar aquellas injusticias que impiden llevar una vida humanamente digna.

Resulta importante comprender desde los procesos de planeación y ordenamiento territorial, que los asentamientos informales son un componente estructural de la ciudad y que la vinculación con lo informal debe superar la visión cartográfica de crear nuevos perímetros urbanos o la puesta economía que termina reflejada en un impuesto predial.

Finalmente, al hablar de víctimas del conflicto armado por desplazamiento forzado a la luz del concepto de justicia espacial, se puede decir que la reparación de las víctimas como una acción de justicia está incompleta. No se trata solo de resolver un techo para ubicarlas y entregarlas a los retos que implica la ciudad, más bien se trata de generar proyectos que permitan desarrollar un hábitat integral y así entregar a la familia un hogar que garantice una vida en condiciones de dignidad.

\section{Referencias Bibliográficas}

Borsdorf, A. (2003). Cómo modelar el desarrollo y la dinámica de la ciudad latinoamericana. EURE 29 (86). Recuperado de https://scielo.conicyt.cl/scielo. php?script=sci_arttext\&pid=S0250-71612003008600002

Ceballos, O., Caquimbo, S. y Rincón, M. (2014). El Desarrollo Humano y la ciudad informal: retos para el planeamiento urbano en Colombia. Ponencia presentada en Seminario Internacional. Nuevas Perspectivas sobre el Desarrollo y Política Pública en América Latina. Pontificia Universidad Javeriana, Bogotá.

Chárriez, M. (2012). Historias de vida: Una metodología de investigación cualitativa. Griot. 5 (1). 50-67. Recuperado de: http://revistas.upr.edu/index.php/griot/article/ view/1775

Cifuentes, E. (2007). El derecho a la ciudad. En: Memorias. Foro de Bogotá. Ciudad latinoamericana y derechos humanos. Bogotá. pp. 45 - 62.

Ministerio de Vivienda, Ciudad y Territorio. (17 de Septiembre de 2012). Decreto 192. Por el cual se reglamentan los artículos $12^{\circ}$ y $23^{\circ}$ de la Ley 1537 de 2012. Bogotá: Registro Distrital: No. 4432, mayo 24 de 2010.

Congreso de la Republica de Colombia (20 de Junio de 2012). Ley 1537. "Por la cual se dictan normas tendientes a facilitar y promover el desarrollo urbano y el acceso a la vivienda y se dictan otras disposiciones" Bogotá: Diario Oficial: No. 48467, junio 20 de 2012.

Congreso de la Republica de Colombia (10 de Junio del 2011). Ley 1448, Ley de Víctimas y restitución de tierras. "Por la cual se dictan medidas de atención, asistencia y reparación integral a las víctimas del conflicto armado interno y se dictan otras disposiciones". Bogotá: Diario Oficial: No. 48096 junio 10 de 2011.

Congreso de la República de Colombia. (2011). Ley 1450, "Por la cual se expide el Plan Nacional de Desarrollo, 2010-2014". Bogotá: Diario Oficial :No. 48102, junio 16 de 2011.

Congreso de la República de Colombia. (1991). Ley 3, "Por la cual se crea el Sistema Nacional de Vivienda de Interés Social, se establece el subsidio familiar de vivienda, se reforma el Instituto de Crédito Territorial, ICT, y se dictan otras disposiciones". Bogotá: Diario Oficial: No. 39.631, 1991.

Defensoría del Pueblo. (2001). ¿Qué son los derechos humanos? Bogotá: Defensoría del Pueblo. Bogotá. 
Delgado, O. (2003). Debates sobre el espacio en la geografía contemporánea. Universidad Nacional de Colombia.

Franco, A. y De los Ríos, I. (2011). Reforma agraria en Colombia: evolución histórica del concepto. Hacia un enfoque integral actual. Cuadernos de Desarrollo Rural. 8 (67): 93-119.

Harvey, D. (1977). Urbanismo y desigualdad social. España: Editores S.A.

Interamerican Development Bank -IDB- y Worl Bank -WB-. (2010). The Quality of Life in Latin American Cities. Markets And Perception. Washington. Recuperado de: $\quad$ https://publications.iadb.org/bitstream/handle/11319/364/9780821378373. pdf?sequence $=1$

Link, F. (2011). Reseña Seeking Spatial Justice. EURE. 37 (111). 173 - 177.

Moreno, A. (2006). En torno a los conceptos de equidad, justicia e igualdad espacial. Huellas 11. 133-142.

Nussbaum, M. (2007). Las fronteras de la justicia. Consideraciones sobre la exclusión. España: Paidós.

Pineda, D. (2017). Una meditación sobre la justicia en Don Quijote de la Mancha. Colección en voz calta. Bogotá: Editorial Pontificia Universidad Javeriana.

Puente, C. (s.f.). Urbanización clandestina: La discusión teórica. Documento de trabajo AGDT/DT005 -03. Centro de proyectos para el desarrollo: Bogotá.

Raffestin, C. (2011). Por una geografía del poder. Trad. Yanga Villagómez Velázquez. El Colegio de Michoacan: México.

Red Nacional de Información. -RNI- (2017). Registro Único de Víctimas. Recuperado de https://rni.unidadvictimas.gov.co/RUV

República de Colombia. (2011). Ley 1448. Ley de Víctimas y Restitución de tierras. Bogotá, Colombia.

Restrepo, M. (2006). Teoría de los derechos humanos y políticas públicas. Tunja: Universidad Pedagógica y Tecnológica de Colombia

Rivera, M y Dulce, L. (16 de Julio de 2017). La capital en deuda con las víctimas. El Espectador. Recuperado de: http://colombia2020.elespectador.com/pais/lacapital-en-deuda-con-las-victimas

Sandel, M. (2014). Justicia. ¿Hacemos lo que debemos? Liderduplex: España.

Secretaria Distrital de Hábitat. (s.f.) Descomposición, caracterización y evolución del Déficit habitacional en Bogotá D.C.

Sen, A. (2010). La idea de la justicia. Taurus: Colombia.

Soja. E. (2010). Seeking Spatial Justice. Universidad de Minnesota: Estados Unidos.

Torres, C. (2009). Ciudad Informal Colombiana. Barrios Construido por la gente. Universidad Nacional de Colombia: Bogotá.

Torres, C. (2007). Ciudad Informal Colombiana. Bitácora Urbano Territorial 11(1). P. $53-93$.

Vidal, R. (2015). La dimensión territorial del pos conflicto en Colombia: debates sobre el ordenamiento territorial transicional. Conferencia. Foro INJAVIU 2015. Políticas Territoriales y de Vivienda: Hacia la construcción de escenarios para la paz. Pontificia Universidad Javeriana- Bogotá. 